\title{
Observational studies of the rock mass response to mining in highly stressed gold mines in South Africa
}

H Ogasawara Ritsumeikan University, Japan

M Nakatani The University of Tokyo, Japan

RJ Durrheim University of the Witwatersrand and CSIR, South Africa

M Naoi Kyoto University, Japan

Y Yabe, H Moriya Tohoku University, Japan

GF Hofmann, C Stander, DP Roberts, P de Bruin, J Oelofse Anglogold Ashanti, South Africa

H Kato 3D Geoscience, Japan

A Cichowicz, D Birch, D Ngobeni Council for Geoscience, South Africa

A Milev, T Kgarume CSIR, South Africa

T Satoh Geological Survey, Japan

S Horiuchi Home Seismo, Japan

H Kawakata, O Murakami Ritsumeikan University, Japan

N Yoshimitsu The University of Tokyo, Japan

AK Ward, J Wienand, P Lenegan Sibanye Gold, South Africa

H Yilmaz, S Mngadi University of the Witwatersrand, South Africa

PS Piper, TN Clements Groundwork Consulting, South Africa

S Nakao Kagoshima University, Japan

M Okubo, H Ishii Tono Research Institute of Earthquake Science, Japan

AV Visser Open House Management Solutions, South Africa

\begin{abstract}
A multi-disciplinary study of the response of the rock mass to mining and mining-induced earthquakes has been conducted in six gold mines in South Africa at sites deeper than $3 \mathrm{~km}$, or with equivalent stress. More than 80 holes (with a total length of more than $2.8 \mathrm{~km}$ ) were drilled in earthquake-prone areas to locate faults and install instruments. Microfracturing activity associated with an $M_{L} 2.1$ event at $3.3 \mathrm{~km}$ depth in Mponeng Mine and a highly stressed rock mass at $1 \mathrm{~km}$ depth in Ezulwini Mine were finely delineated and analysed. A hole drilled through the hypocentre of the ML2.1 event at Mponeng Mine allowed the stress and strength in the seismogenic area to be constrained. Previously published in situ stress measurements had been limited to depths or stresses smaller than $2.7 \mathrm{~km}$ or $100 \mathrm{MPa}$, respectively. We successfully measured stress at depths and stresses up to $3.4 \mathrm{~km}$ and $146 \mathrm{MPa}$, respectively, at four mines. These in situ measured stresses were used to calibrate elastic stress modelling and yielded better estimates of stress and strength on the rupture planes of seven earthquakes (ML2.1 to 4). Comparison of the elastically modelled stress with the constrained stress in a hole drilled across the $M_{L} 2.1$ fault and the strain change monitored in situ at a close distance showed that the elastically modelled stress was smaller but correctable.

The South African National Seismograph Network was enhanced by installing 10 surface strong-motion seismometer stations in the Far West Rand mining district. Two other such dense surface networks are
\end{abstract}


currently operated in mining areas by the Council for Geoscience: 25 stations in the Klerksdorp region, supported by the Mine Health and Safety Council; and 17 stations in the Central Rand to monitor fluid-induced seismicity. Research on the routine processing of spectral parameters was carried out using seismicity recorded by these 52 new surface stations.

\section{Introduction}

Gold production in South Africa has decreased sharply in recent years, although large ore resources remain in highly stressed pillars and at depths exceeding $4 \mathrm{~km}$. This ore can only be mined if the risk posed by seismicity is overcome. Furthermore, Japanese seismologists are eager to monitor the rock mass in close proximity to earthquake hypocentres to gain a detailed understanding of nucleation and rupture processes. For those purposes, the Japanese-South African collaborative research work on mining-induced seismicity, which started in 1992 (Nicolaysen 1992), has been conducted on an increasing scale since 2009 (Ogasawara et al. 2009). The research has aimed to understand better the response of the rock mass to mining in highly stressed gold mines in South Africa; and how fault zones nucleate, evolve with time and loading, rupture, and generate violent seismic waves.

Here we describe research work that is being conducted at six underground sites: a $1 \mathrm{~km}$ deep shaft pillar (maximum principal stress, $\sigma_{1}>\sim 100 \mathrm{MPa}$ ); three sites at 3-3.3 $\mathrm{km}$ depth, two beneath dip pillars, and the third beneath a regional pillar where $\sigma_{1}$ increased by several tens of MPa from its initial state due to mining; and two sites at 2.9-3 km depth in highly faulted ground. More than 80 holes with a total length exceeding $2.8 \mathrm{~km}$ were drilled to locate faults and install the instruments. These included acoustic emission $(A E)$ sensors, sensitive strain and tilt meters, dynamic stress-change sensors on the potential rupture front, and an array to monitor waves transmitted through the fault zone (Figure 1). In stopes, the Council for Scientific and Industrial Research (CSIR) has installed stope closure meters and strong ground motion meters. On the surface, stations were added to the South African National Seismic Network, operated by the Council for Geoscience (CGS). The establishment of the research sites were described at the Sixth International Deep and High Stress Mining Seminar by Durrheim et al. (2012). Here we review the most significant findings since 2012: the measurement of in situ stress at levels that are more extreme than any previously published measurements (Section 2); the monitoring of acoustic emissions and the evolution of fracture zones (Section 3); and the enhancement of the national surface seismograph network (Section 4).

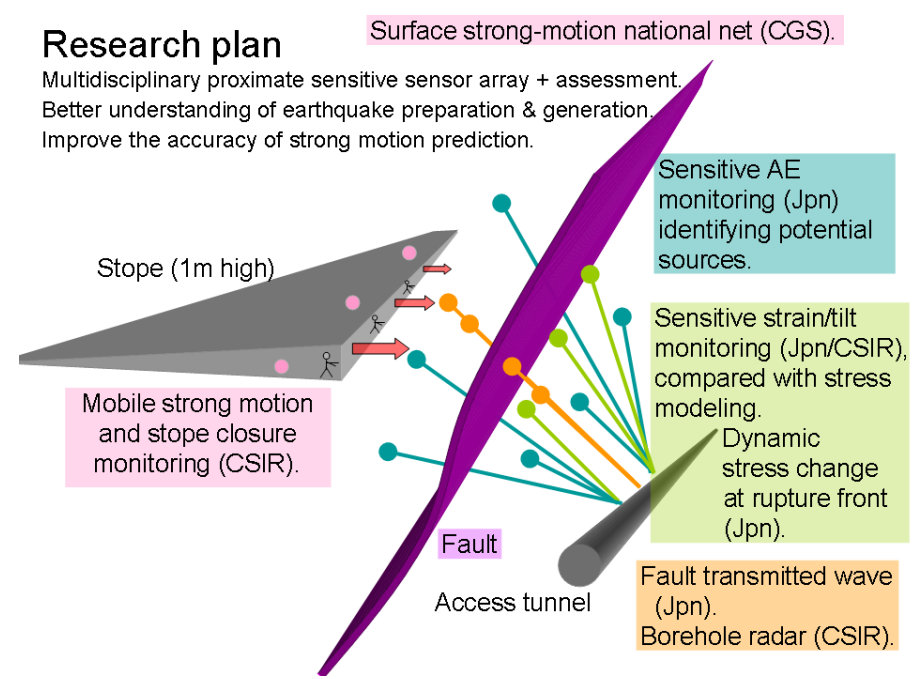

Figure 1 Schematic illustration of the research design. Jpn: Japanese researchers, CSIR: Council for Scientific and Industrial Research, CGS: Council for Geoscience 


\section{$2 \quad$ In situ stress measurements and stress modelling}

\subsection{Implementation of a modified method of in situ stress measurement}

In order to mine as much gold as possible without compromising safety, it is essential to optimise the geometry and sequence of mining. Accurate stress information is critical when designing layouts to mine at great depths and extract remnants and pillars. However, it is often difficult to carry out in situ stress measurements because of borehole breakout or core discing. While it may be possible to find a drilling direction that has a reduced chance of borehole breakout or core discing, several difficulties remain:

The stress estimation methods that rely on laboratory testing of the borehole core (e.g. Kaiser effect or deformation rate analysis (DRA); Amadei \& Stephansson 1997; Yamamoto et al. 1990, respectively) are difficult to use because the core must be loaded in compression to stress levels beyond the onset of dilatancy. It is difficult to identify the onset of subtle change that indicates in situ stress.

The hole must be sub-parallel to the maximum principal stress, $\sigma_{1}$. Consequently, the hydrofracturing method cannot be used to determine the $\sigma_{1}$ because the method determines the stress in the plane perpendicular to borehole axis. Should a hole be drilled so that $\sigma_{1}$ is on the plane perpendicular to the borehole axis, borehole breakouts will occur and prevent hydrofracturing.

The overcoring methods conventionally used in South Africa, e.g. the CSIRO HI technique (Kim \& Franklin 1987) or CSIR triaxial strain cell method (Leeman \& Hayes 1966), need high quality larger diameter drilling, which limit the number of measurements. Limited choice of drilling direction tends to result in longer hole length in order to be sufficiently far from tunnels or openings to measure stress, which further makes it difficult to measure stress quickly.

As reported by Gay (1975) and more recently by Wesseloo and Stacey (2006), very little in situ stress data has been published for each gold mining district. The hatched area in Figure 2 shows the ranges of principal stresses and depths previously published and compiled by Handley (2013), who selected from the databases of Stacey and Wesseloo (1998). It is noted that there are no published results at depths larger than $2.7 \mathrm{~km}$ or at stresses larger than $100 \mathrm{MPa}$.

On a typical major gold mine, a few tens of crews are continuously conducting geological drilling with small pneumatic machines. In order to enable overcoring with BX size bits (60 mm diameter), Ogasawara et al. (2012) modified the ISRM-approved compact conical-ended borehole overcoring (CCBO) technique (Sakaguchi et al. 1992; Sugawara \& Obara 1999) that was originally designed for NX drilling (76 mm diameter). A strain cell consisting of 16 or 24 strain gauges is glued to the conically-shaped borehole end and overcored using the same bit that was used to drill the pilot hole. A 3D stress tensor can be determined with a single $10 \mathrm{~cm}$ overcoring. All procedures for an overcoring took only $2 \frac{1}{2}$ hours, proving suitable for deep levels South African deep level gold mines where underground working time is limited.

\subsection{Calibration of elastic stress modelling}

Lucier et al. (2009) attempted to model in situ stress in Tau Tona Mine. They began by assuming that $\sigma_{1}$ is vertical, $\sigma_{2}$ and $\sigma_{3}$ are horizontal, and that all stresses increase linearly with depth. Modelling mining-induced stress, they then adjusted the assumption until they could best account for the breakout observed in a $418 \mathrm{~m}$ long hole drilled into virgin ground from 118 Level at the Natural Earthquake Laboratory in South African Mines (NELSAM) site, $3.3 \mathrm{~km}$ below surface (L118 in Figure 2). The orientations of $\sigma_{2}$ and $\sigma_{3}$ obtained from an in situ stress measurement in the Tau Tona shaft pillar that had been made in 2000 (Tau Tona L83 in Figure 2) were also taken into account. The stress gradient thus constrained is hereafter referred to as 'NELSAM' (solid lines in Figure 1).

As detailed by Ogasawara et al. (2013), two BX CCBO stress measurements were carried out at sites undisturbed by mining or geological structures at depths of 3,362 and 3,325 m (CCBO L120 and CCBO L115 in Figure 2) at Tau Tona and Mponeng mines in January and February 2013, respectively. The drilling 
directions were carefully designed to minimise the risk of borehole breakout or core discing. It was then found the assumption of Lucier et al. (2009) had to be modified, as shown by a dashed line in Figure 2(a).

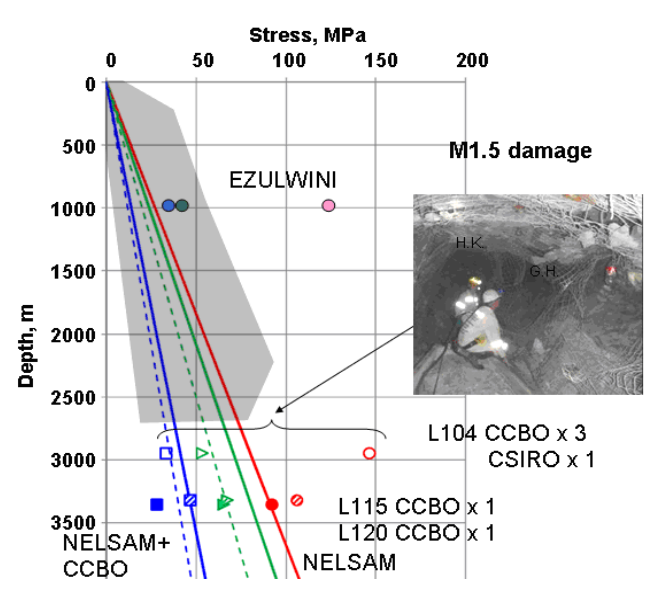

(a)

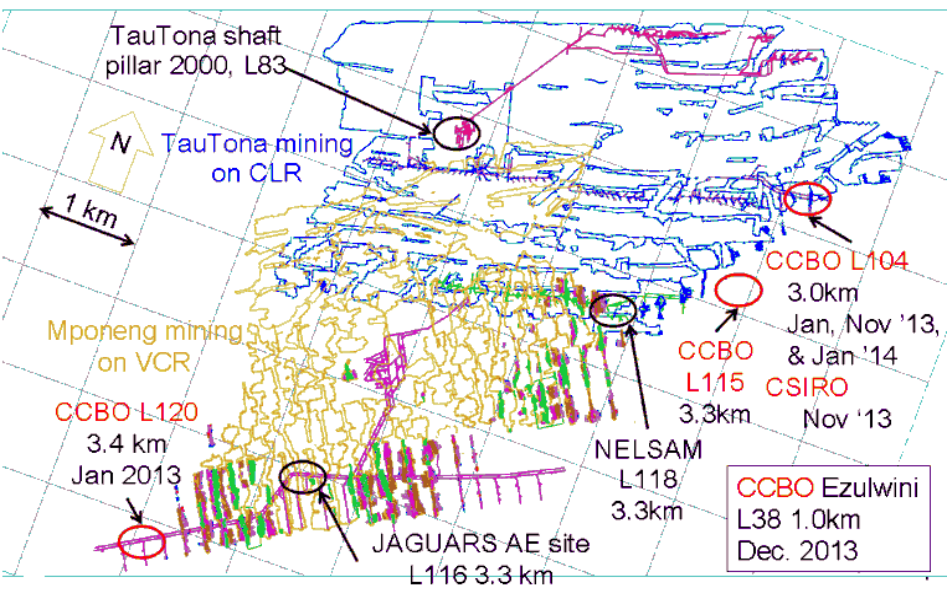

(b)

Figure 2 (a) in situ measured principal stresses versus depth from surface. The shaded area represents the range of the previously published principal stresses measured in South Africa (Stacey and Wesseloo 1998; Handley 2013). The solid lines represent vertical gradients of principal stresses in virgin ground proposed by Lucier et al. (2009) based upon the comparison between elastically modelled stress and the borehole breakout in a $418 \mathrm{~m}$ long hole drilled east-southeast to the virgin ground from the site labelled NELSAM in Figure 2(b). Open symbols represent in situ stresses measured by Ogasawara et al. (2013, 2014b) at 104 level at Tau Tona Mine (L104) near damage caused by an $\mathrm{M}_{\mathrm{L}} 1.5$ event (see inset photo). Three BX CCBO and one CSIRO measurements were carried out at different distances from the tunnel and hole inclinations. (b) Locations of in situ measurements (modified from Ogasawara et al. 2014b)

\subsection{Comparison of elastic stress modelling with in situ strain monitoring}

Several BX CCBO measurements were carried out at a site on 104 level at Tau Tona Mine (L104 in Figure 2) near damage caused by an $\mathrm{M}_{\mathrm{L}} 1.5$ seismic event. Breakouts prevented us from measuring stress in the first hole. A second hole ( $(\mathrm{L} 104 \mathrm{H} 2)$ was drilled with a different bearing, and very high stress was measured by the BX CCBO method at a distance of $5 \mathrm{~m}$ (c.f. a section of the tunnel was about $3.5 \times 3.5 \mathrm{~m}$ ). As the shallow measurement depth was suspected to cause the high stress, two more measurements were carried out by the BX CCBO and CSIRO methods (CSIRO and L104 H5 in Figure 3) at significantly larger depths in holes with the same bearings and significantly larger inclination, but the collars just $2 \mathrm{~m}$ from Hole 2 collar, and an additional BX ССВO measurement was made several tens of metres from Hole 2. Figure 3 shows a plot of the measured principal stresses against the elastically modelled stress. Except for one measurement of maximum principal stress (Sigma 1 for $104 \mathrm{H} 2$ in Figure 3), all the measurements were in good agreement with the modelled stress, although most Sigma 3 values are slightly smaller than expected.

\subsection{In situ stress measurement in a $\mathbf{1} \mathbf{~ k m}$ deep shaft pillar at Ezulwini Mine}

BX ССBO measurements were carried out in the centre of the eastern part at a shaft pillar at $1 \mathrm{~km}$ depth, which remained after the completion of the extraction of the western part of the shaft pillar. The direction of the hole was carefully determined ( 35 degree up and almost normal to the reef). Minor breakouts were observed on the sidewall, but no breakout or discing at the conical-end of the borehole. The strain relief curves were smooth, suggesting that there was no inelastic behaviour during overcoring. The stress thus determined was found to be as high as the stress in virgin ground at a depth of $3 \mathrm{~km}$ or more, as shown in 
Figure 2(a). The acoustic emission activity observed during the extraction of the western part of the shaft pillar will be detailed in Section 3.2.

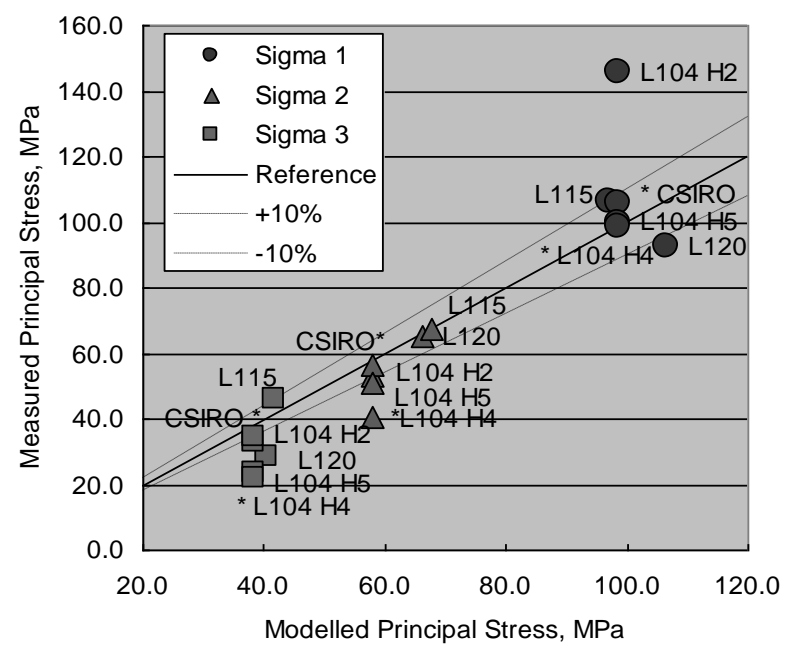

Figure 3 In situ measured stress versus the modelled stress (Ogasawara et al. 2014b)

\subsection{Stress at hypocentres}

As detailed in Section 3.1.2, using the NELSAM assumption (solid lines in Figure 2), Hofmann et al. (2012) confirmed that the modelled fault ride is in good agreement with the rupture plane that was accurately delineated by a local AE network. Hofmann et al. (2012) also investigated the stress at the hypocentre of an $M L 2.1$ event. Hofmann et al. (2013) estimated the stress for seven earthquakes $\left(M_{L}=2.9-4\right)$ using the modified NELSAM assumption as a constraint (dashed lines for Sigma 2 and 3). Sigma 1 was found to range between 100 and $177 \mathrm{MPa}$.

Therefore, the 128 and 146 MPa measured at Ezulwini and Tau Tona, respectively, is in the range of stress at the above hypocentres. This confirms that stress measurements at hypocentres are possible by the BX CCBO method if the hole direction is carefully chosen.

\section{$3 \quad$ Acoustic emission monitoring and associated studies}

\subsection{Japanese-German Underground Acoustic Research in South Africa (JAGUARS) and subsequent associated researches}

\subsubsection{AE network and a very close $M_{L} 2.1$ event}

Nakatani et al. (2008) deployed a network consisting of eight AE sensors to monitor the microfracturing activity in a volume of about $300 \times 300$ ? $300 \mathrm{~m}^{3}$ beneath a dip pillar containing a $30 \mathrm{~m}$ thick dyke at $3.3 \mathrm{~km}$ depth at Mponeng Mine (JAGUARS in Figures 2(b) and 4(b)). The AE sensors, which were installed in boreholes drilled from a horizontal tunnel intersecting the dyke, had a response up to $200 \mathrm{kHz}$, and could detect events down to $M_{w}=-4.4$ (Kwiatek et al. 2010). A triaxial accelerometer with flat response up to $25 \mathrm{kHz}$ was installed to calibrate the non-flat frequency characteristics of the AE sensors, allowing moment magnitudes to be determined and self-similarity to be studied. In situ measurement of Vp and Vs confirmed that the dyke was stiffer than the host rock (Naoi et al. 2008). Due to the mining of the thin tabular gold reef dipping about $20^{\circ}$ to the south-southeast $90 \mathrm{~m}$ above the network, significant seismicity was induced, which included an ML2.1 event just above the network on 27 December $2007\left(\mathrm{M}_{\mathrm{w}} 1.9\right.$ by the in-mine seismic system and referred in Yabe et al. (2009) and Kwiatek et al. (2010, 2011); $M_{w} 2.2$ in Naoi et al. (2011)). An abrupt increase in AE activity produced more than 20,000 events in the 150 hours following the $M_{\llcorner} 2.1$ event, delineating the planar rupture plane of the $M\llcorner 2.1$ event (see a line intersecting the dyke obliquely in 
Figures 4 and 5(a)) as well as activity around the tunnel, ahead of the closest mining face, and other regions. The planar AE distribution was consistent with the fault mechanism that Naoi et al. (2011) determined by Centroid Moment Tensor analysis. The details on the microfracturing characteristics and statistics of microfracturing in space and time, and the implications for self-similarity in source parameters and other observations have been discussed and documented in detail by Yabe et al. (2009), Naoi et al. (2011), Kwiatek et al. (2010, 2011), and Plenkers et al. $(2010,2011)$.

Here we summarise the results of our subsequent studies, which include a comparison of the $M_{L} 2.1$ rupture with numerically-modelled fault ride assuming peak and residual strength (Hofmann et al. 2012) and the drilling of a borehole into the $\mathrm{M}_{\mathrm{L}} 2.1$ hypocentre (an arrow in Figures 4 and $5 \mathrm{a}$ ) to constrain stress by analysing borehole breakout and core discing (Yabe et al. 2013; Figure 5). Taking these into account, Ogasawara et al. (2014a) discussed the recordings of two borehole strainmeters that had been installed in $10 \mathrm{~m}$ holes drilled into the dyke and the host rock (Sd and Sh in Figures 4 and 5(a), respectively) from the crosscut tunnel several months prior to the $\mathrm{M}_{\mathrm{L}} 2.1$ event, which were sensitive enough to detect earth tides and have a capacity of up to a thousand micro strain (corresponding to stress change of about $70 \mathrm{MPa}$ ).

\subsubsection{Stress and strength on the ML2.1 fault}

Hofmann et al. (2012) made use of Map3D (Wiles 2010) to model the time evolution of stress and strain due to mining, searching for peak and residual strengths on a displacement discontinuity plane (a line obliquely intersecting the dyke in Figures 4 and 5a) that coincided with the $\mathrm{ML}_{\mathrm{L}} 2.1$ rupture plane so that a fault ride corresponding to the seismically-determined seismic moment occurred after the completion of the mining step of December 2007. An in situ stress measurement $2 \mathrm{~km}$ to the west of the dyke at $3.4 \mathrm{~km}$ depth with little geological or mining disturbance (L120 in Figures 2 and 3) confirmed that the initial stress assumed in Hofmann et al. (2012) was acceptable. Figure 4 shows the maximum shear stress after the completion of the mining step and the occurrence of the ride corresponding to the $M_{L} 2.1$ event. The following were confirmed:

- Stress inside the dyke increased.

- The $\mathrm{M}$ 2.1 rupture plane was located in the area with the largest Excess Shear Stress (ESS).

- The peak and residual strength parameters (cohesions $=12.2$ and $0 \mathrm{MPa}$, and friction angles of 25 and $28.5^{\circ}$, respectively) determined by Hofmann et al. (2012) were consistent with previous studies by Hofmann and Murphy (2007), and Hofmann and Scheepers (2010), which had remained unconfirmed because of the limited accuracy in hypocentre location of the in-mine seismic system.

In summary, Hofmann et al. (2012) and Yabe et al. (2013) found:

- The stress increased suddenly inside the dyke, with an additional increase on the hanging wall side of the $M_{L} 2.1$ rupture plane (Figures 4 and 5).

- The direction of the principal stress was consistent with the faulting associated with the $M\llcorner 2.1$ event.

The magnitude of the stresses constrained by Yabe et al. (2013) were larger than those estimated by Hofmann et al. (2012).

The loading (strain change) that Ogasawara et al. (2014a) monitored in situ was also significantly larger than those modelled elastically by Hoffman et al. (2012). It is known that elastic stress modelling cannot reproduce inelastic relaxation just ahead of the edges of tabular stopes (note unrealistically high stress ahead of the stope edge in Figures 4 and 5(a)) or the effect of time-dependent closure of tabular stopes. Ogasawara et al. (2014a) attempted to add a forced stope closure in the Map3D model to reproduce the effect of time-dependent stope closure in an elastic volume outside the inelastic area. The magnitude of strain change was then successfully taken into account. 
The number of localities where Yabe et al. (2013) and Ogasawara et al. (2014a) could study stress and deformation was limited: stress at twelve depths along a hole (an arrow in Figures 4 and 5(a)) and strain in two boreholes (Sd and Sh in Figures 4 and 5(a)), respectively. Therefore, it is desirable to increase the number of in situ data to further discuss heterogeneity or accuracy of modelling of stress and strength in seismogenic volume.
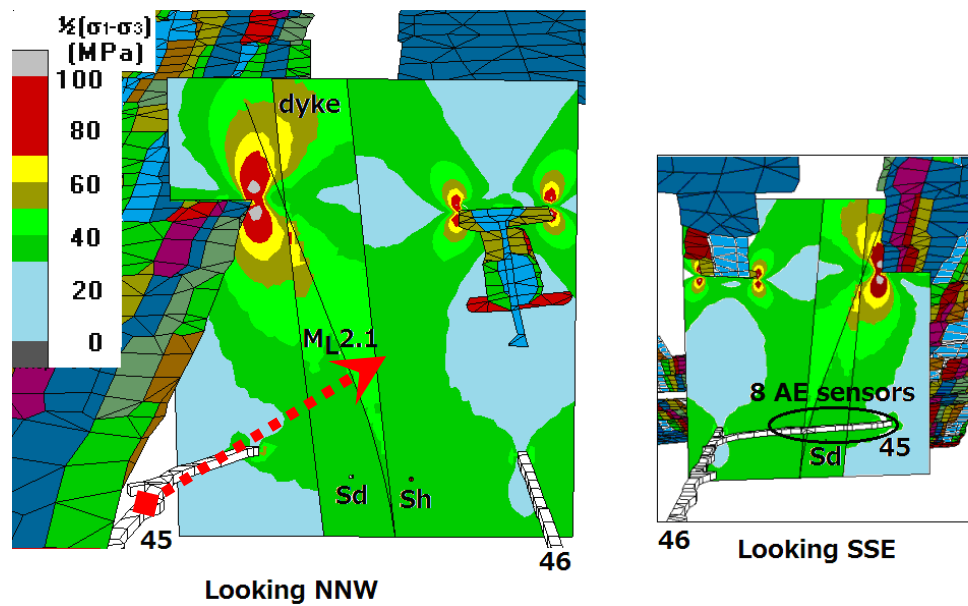

Figure 4 Perspective views towards the NNW (up-dip direction of the thin tabular stope) and SSE (down-dip direction) to illustrate the configuration of the horizontal crosscut tunnels (45 and 46 ), thin tabular stopes dipping SSE, an area where eight AE sensors were installed by Nakatani et al. (2008), two strainmeters (Sd and $\mathrm{Sh}$ ), and a $90 \mathrm{~m}$ hole intersecting the $\mathrm{M}_{\mathrm{L}} 2.1$ hypocentre (a dotted line with an arrow). Also shown is the distribution of maximum shear stress just after the completion of the mining step in December 2007 when the $M_{L} 2.1$ took place. A line represents a plane of displacement discontinuity elements on the $M_{L} 2.1$ rupture plane that Hofmann et al. (2012) specified to calculate stress and ride

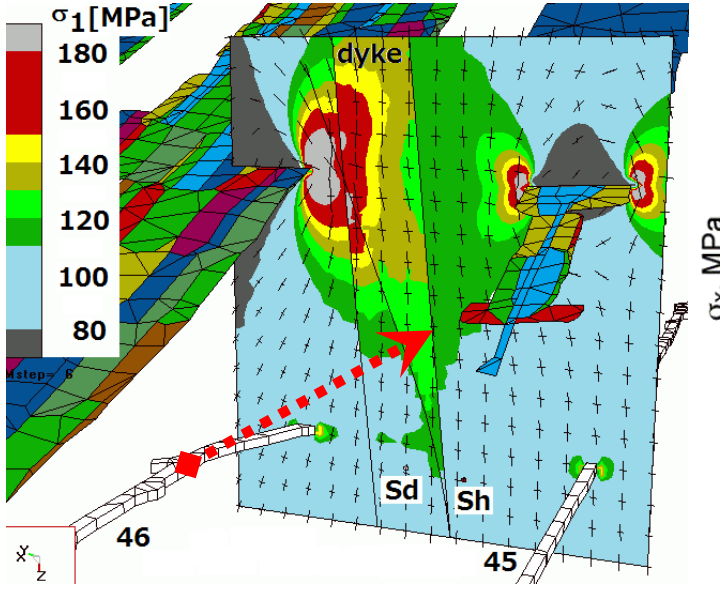

(a)

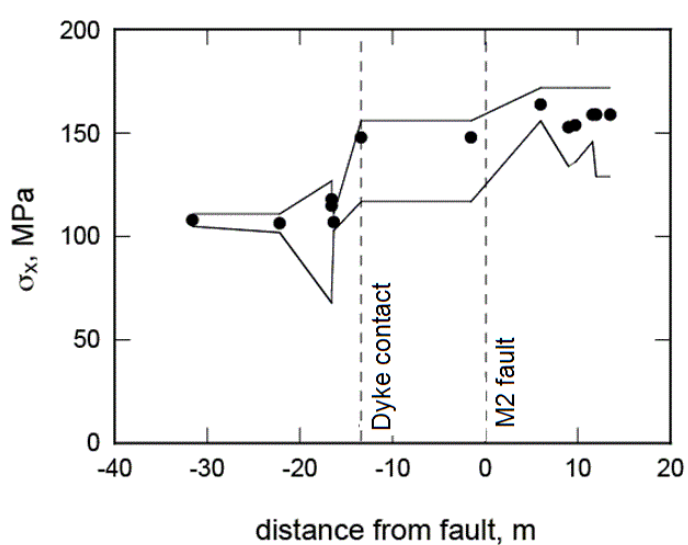

(b)

Figure 5 (a) stress estimated by Hofmann et al. (2012); and (b) the maximum principal stress Yabe et al. (2013) constrained on the plane perpendicular to the axis of the hole intersecting the ML2.1 hypocentre (an arrow)

\subsubsection{Comparison with laboratory experiment}

Satoh et al. (2013) conducted a laboratory triaxial compression experiment on a cylindrical gabbro sample $(4 \mathrm{~cm}$ diameter and $10 \mathrm{~cm}$ length) collected from the dyke. Figure 6 shows the AE distributions (vertical section) for (a) the $M_{\llcorner} 2.1$ aftershocks (Naoi et al. 2011), and (b) the core just prior the final failure (Satoh et al. 2013). Very interestingly, the angles of the fracture planes were almost identical. Some other important 
information is summarised in Table 1, which will allows us to discuss scale dependency and the inherent difference between

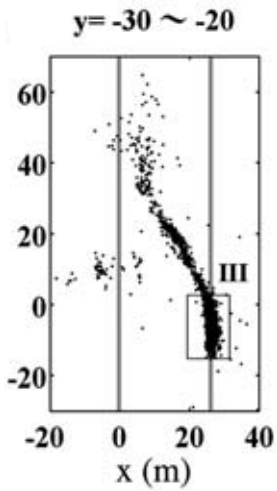

(a)

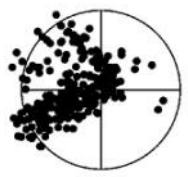

(b)

Figure 6 Comparison of ruptures at field and laboratory scales. See also Table 1. (a) $M_{L} 2.1$ rupture in the dyke (Naoi et al. 2011); and (b) laboratory rupture (modified from Satoh et al. 2013)

Table 1 Comparison between the gabbro ruptures in the $M_{\llcorner} 2.1$ and laboratory scales

\begin{tabular}{|c|c|c|}
\hline & $\begin{array}{l}\sim 100 \mathrm{~m} \text { scale (ML2.1 at Mponeng) } \\
\text { (Naoi et al. 2011) }\end{array}$ & $\begin{array}{l}4 \mathrm{~cm} \text { diameter } \times 10 \mathrm{~cm} \text { length } \\
\text { (in lab) (Satoh et al. 2013) }\end{array}$ \\
\hline Rock & Dyke (gabbro) & Intact gabbro collected in the dyke \\
\hline Loading & $\sim 1$ micro strain /day & $\sim 1$ micro strain / s \\
\hline Nucleation size & Several tens of $\mathrm{m}$ & $2 \times 5 \mathrm{~cm}$ \\
\hline $\begin{array}{l}\text { AE just prior to } \\
\text { the final failure }\end{array}$ & $\begin{array}{l}\text { Apparently no acceleration } \\
\text { as a whole }\end{array}$ & $\begin{array}{l}\text { Accelerated as often seen } \\
\text { in lab experiments }\end{array}$ \\
\hline Final fracture & Almost identical angle to each other & \\
\hline \multirow[t]{2}{*}{ Strength } & 160 MPa calculated & $\sim 600 \mathrm{MPa}$ measured \\
\hline & $\begin{array}{l}\text { for } 75 \mathrm{MPa} \text { confining pressure based } \\
\text { on the strength Hofmann et al. (2012) } \\
\text { constrained for the } \mathrm{ML} 2.1 \text { fault }\end{array}$ & $\begin{array}{l}\text { in laboratory } \\
\text { under } 75 \mathrm{MPa} \text { confining pressure }\end{array}$ \\
\hline Stress drop & $3 \mathrm{MPa}$ (Naoi et al. 2011) & $600 \mathrm{MPa}$ \\
\hline
\end{tabular}

\subsection{Enhanced AE network in a shaft pillar at Ezulwini Mine}

The response of the rock mass to mining has been monitored in a multidisciplinary experiment at Ezulwini Mine in the shaft pillar (a circular white area of about $500 \mathrm{~m}$ (east-west) $\times 400 \mathrm{~m}$ (north-south) in Figure 7(a); Nakatani 2013). Although the depth of the pillar is only $1 \mathrm{~km}$ from surface, high stress is expected due to the mining prior to 2001 as shown in dark blue in Figure 7(a). About 30 holes with a total length exceeding $1 \mathrm{~km}$ were drilled to locate the target fault and install sensors. Nakatani (2013) installed $28 \mathrm{AE}$ sensors in a three-dimensional volume with an extent of $100 \mathrm{~m}$ (north-south) $\times 50 \mathrm{~m}$ (east-west) $\times 30 \mathrm{~m}$ (depth). The frequency band of response of the $A E$ sensors was only up to $50 \mathrm{kHz}$, which is much lower than AE sensors used in the JAGUARS project $(200 \mathrm{kHz})$, but the sensors could detect events down to $M_{w}-5$. The $A / D$ rate was $500 \mathrm{kHz}$, allowing precise location.

The events recorded were too numerous to process manually. Automatic travel-time detection software developed by Home Seismometer Corp., Japan (Horiuchi et al. 2011) was used. The method first picks several candidates for the arrival time of each $\mathrm{P}$ and $\mathrm{S}$-wave by gradually lifting threshold levels. The method then characterises the ground motion that follow each candidate arrival time, in order to 
distinguish between direct seismic phases ( $\mathrm{P}$ and associated $\mathrm{S}$-waves) that can be used to determine the hypocenter of an earthquake or fracture in the rock; or ground motion produced by noise, or refracted, reflected or surface waves, which must be excluded. The characterisation parameters include the predominant frequency, the ratio between the amplitudes of the horizontal and vertical components, the time differences among the candidate arrivals, the $\mathrm{S} / \mathrm{N}$ ratio, and the ratio of the amplitude of the candidate phase to the maximum amplitude in the period after the $\mathrm{P}$ or $\mathrm{S}$-arrivals. It then uses an evaluation function, based on seismological knowledge, to select the best-fitting $\mathrm{P}$ and $\mathrm{S}$-arrivals amongst the candidates. The initial and threshold values in the evaluation equations are empirically determined. An iterative process is used to minimise the differences between about 10,000 manual P and S-arrival picks and picks determined by the evaluation function.

Not only was distinctive AE activity ahead of the mining face observed, but also planar AE clusters were also delineated, as shown in Figure 7(b).

To correct the non-flat frequency characteristics of the AE sensors, three $25 \mathrm{kHz}$ triaxial accelerometers were also installed, allowing the seismic moment of the AEs to be determined. Naoi et al. (2013) confirmed that the $b$-value for the AEs ( $\mathrm{Mw}=-3.7$ to 0 ) ahead of stopes is about 1.2 (Figure 8). This contradicts the suggestion by Richardson and Jordan (2002) that new fractures generated by blasting perturb the size distribution of background events. Richardson and Jordan (2002) analysed a large number of in-mine seismic data that covered the entire mines. However, the location accuracy and detection limit of the data were not uniform over the mines. In addition, the location accuracy was much lower and the detection threshold much higher than for the AE data Naoi et al. (2013) analysed.

Moriya et al. $(2012,2013)$ attempted to delineate the AE structures more finely (Figure 9) by using the Joint Hypocenter Determination (JHD) and the Collapsing methods (Jones \& Stewart 1997). The typical geological perception of fracturing around a stope is well illustrated, e.g. Chamber of Mines Research Organization 1988. However, because time evolution can be tracked in AE data, the forthcoming AE research will allow us to describe, in detail, the time evolution of fracturing and stress due to mining.

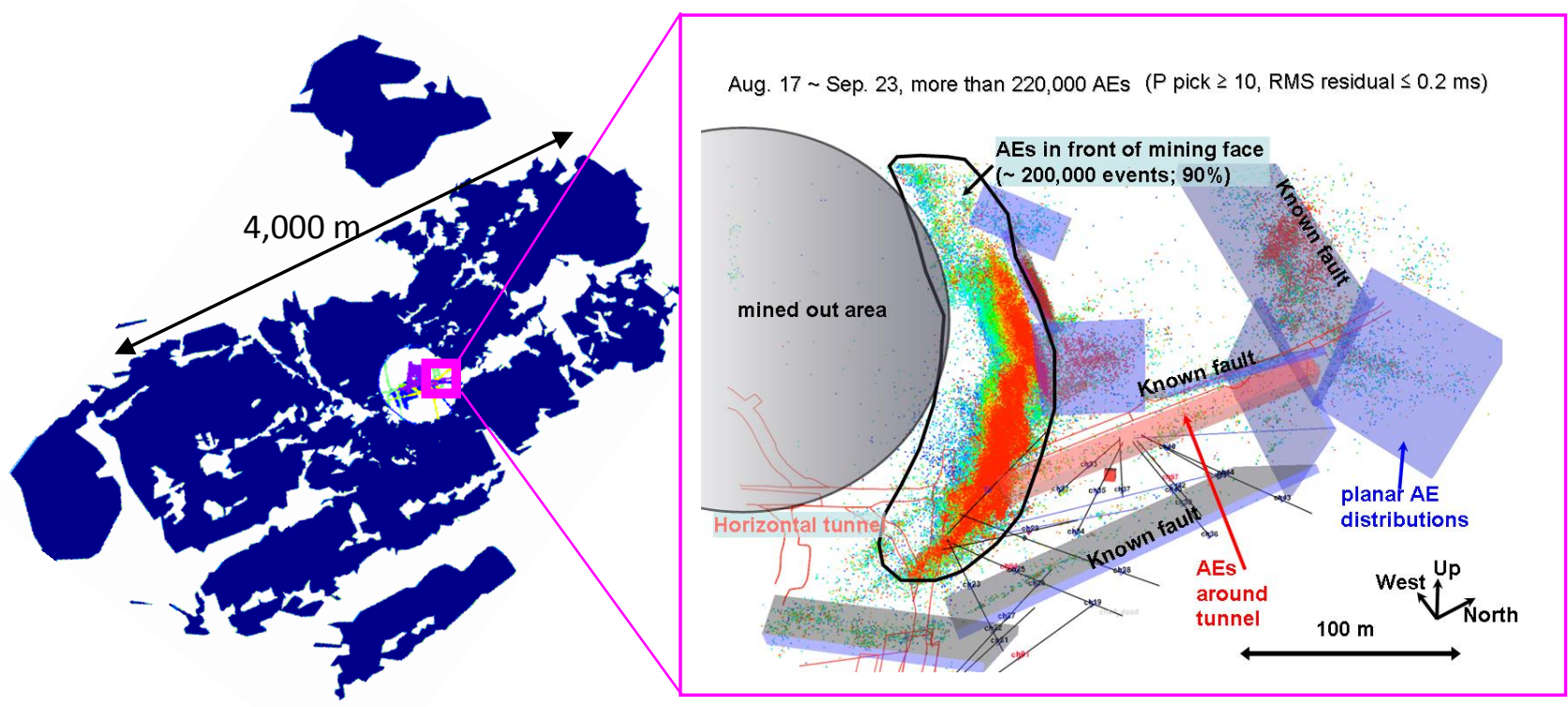

(a)

(b)

Figure 7 (a) plan of Ezulwini Mine. The shaft pillar (white circular area in the middle) is about $1 \mathrm{~km}$ deep and surrounded by old stopes (dark blue) that were not backfilled. The location of the AE network of Nakatani (2013) is shown by a small rectangle; (b) planar structures delineated by AE monitoring (perspective view) 


\section{0:00-14:00, 19:00-24:00 Mon-Sat, all day Sundays}

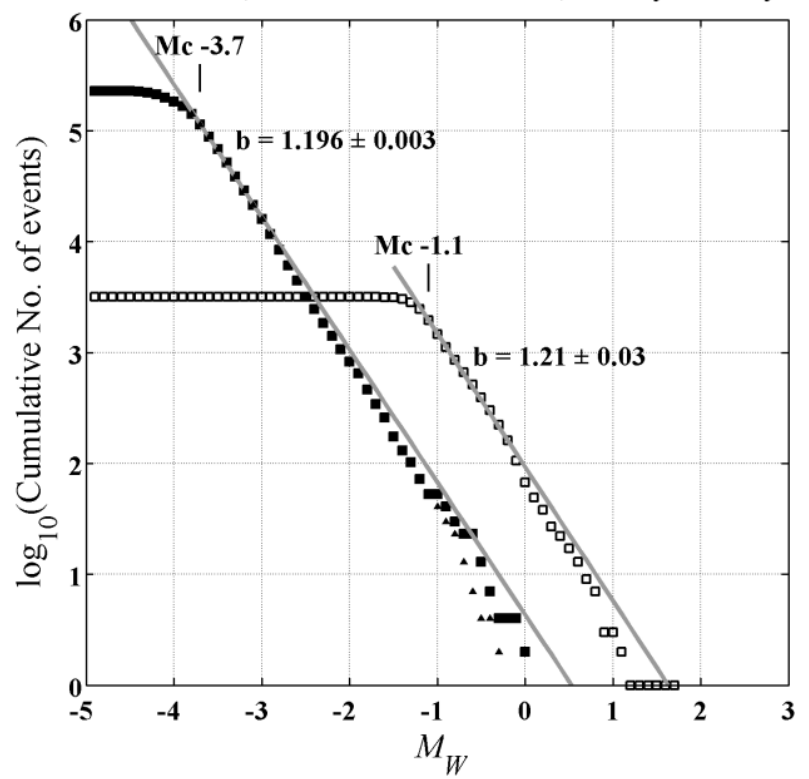

Figure 8 Frequency plotted versus moment magnitude of AEs and seismic events at Ezulwini Mine (Naoi et al. 2013). Solid squares represent AEs just ahead of a stope panel during non-blasting hours. Small solid triangles represent raw data without correction for underestimation. Open squares represent seismic events detected by the in-mine seismic system over the entire mine

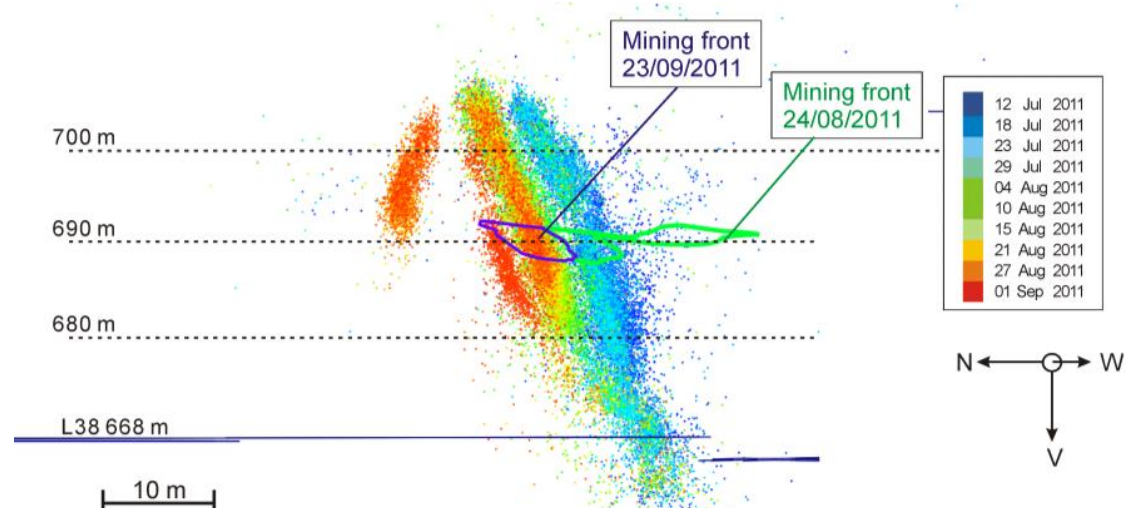

(a)

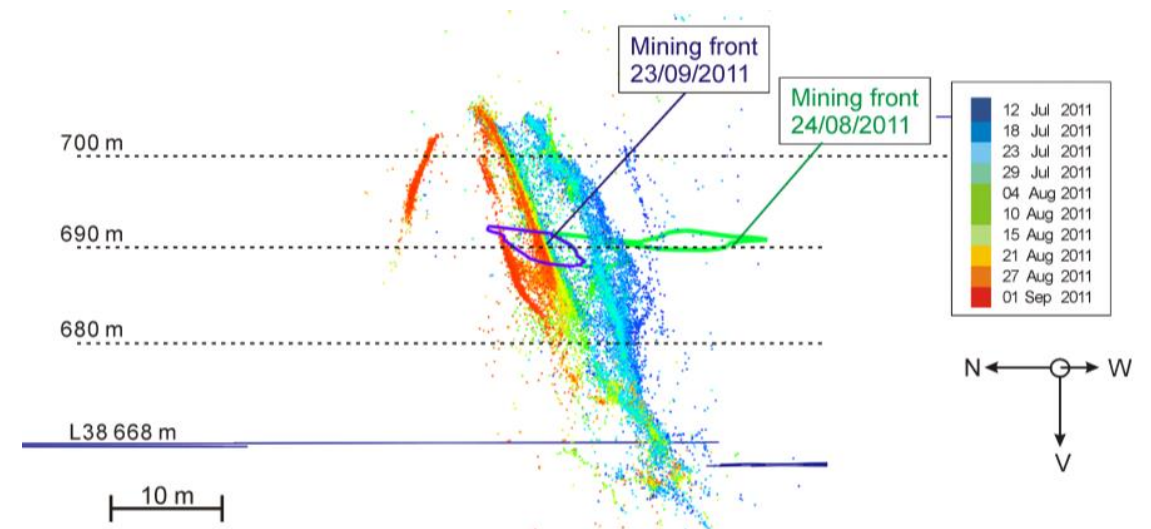

(b)

Figure 9 (a) vertical sectional view of AE source locations by the JHD method; and (b) the collapsing method (Moriya et al. 2013) 


\section{$4 \quad$ Enhanced national surface seismograph network}

The CGS now operates three dense strong motion seismograph surface networks in the Klerksdorp (KO in Figure 10), Far West Rand (FW in Figure 10) and Central Rand (SW in Figure 10) mining areas of South Africa. A total of 52 seismograph stations were installed. A modern data acquisition system was introduced that improves data acquisition and processing and also provides automatic seismic event location. The locations produced by this system were not initially very useful. Recently, an improved automatic event location algorithm by Horiuchi et al. (2011) was introduced, producing very good clustering of seismic events within mining boundaries without the problem of spurious and false locations (Figure 10(b)). Data recorded for the month of March 2014 were plotted to compare the current and new automatic location capabilities.

The results from the improved automatic event location algorithm by Horiuchi et al. (2011) were very pleasing and will assist in the manual picking of events. The original data acquisition system is constantly being improved. The CGS has changed operating systems from Macintosh to Linux and methods to improve data extraction were developed. Work on the routine processing of spectral parameters has produced results and work on producing moment tensor solutions from data in the Central Rand is underway.

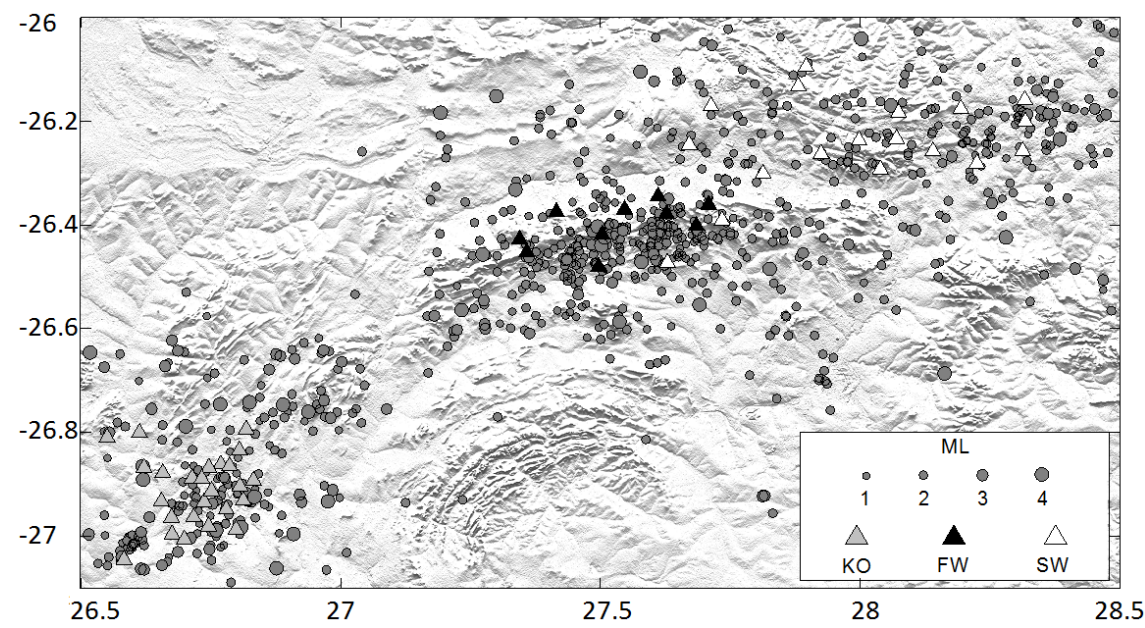

(a)

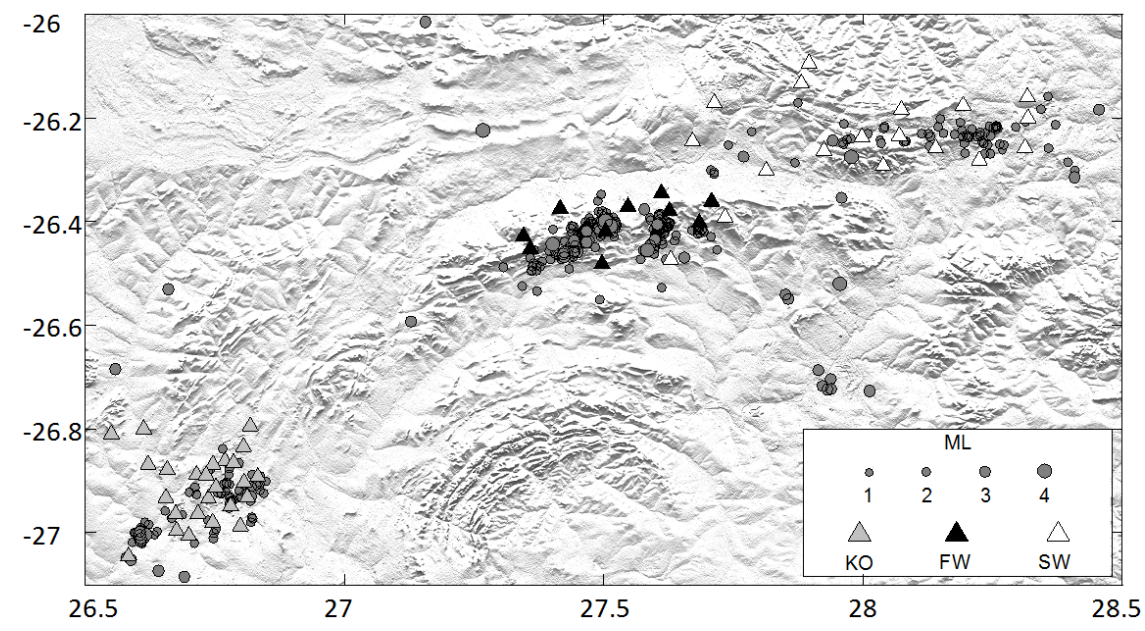

(b)

Figure 10 (a) comparison of automatic locations for the month of March 2014 with the current system; and (b) with the algorithm of Horiuchi et al. (2011)

The observed ground motion generated by induced earthquakes is affected by the source, travel path, and local site conditions. The attenuation of the $\mathrm{P}$ and $\mathrm{S}$-waves is estimated by using the coda normalisation methods (Aki 1980; Chapter 3.3 in Sato et al. 2012). The method was chosen as estimation of the 
$Q(f)=Q_{0} f^{n}$ is not affected by seismic source parameters and site effect, where the values of ' $Q_{0}$ ' and ' $n$ ' are estimated using linear regression. The coda normalisation method was extended to include optimal parameters of the geometrical spreading with piecewise segments. To be able to estimate spectral parameters in an automatic and robust way the observed spectra after correction for the path and site effect are processed using the integrals of Andrews (1986) for each event spectrum.

The developed program calculates the following parameters of the seismic source: scalar seismic moment, $M_{w}$ magnitude, radiated seismic energy, corner frequency, source radius, apparent stress and static stress drop. The windows with the P-wave and S-wave groups are automatically extracted for all suitable waveforms to provide robust estimation of seismic source parameters. The results of routine processing indicate that the reliable estimation of source parameters of earthquakes can be achieved for distances of less than $80 \mathrm{~km}$ between seismic source and stations. A catalogue of almost 1,000 earthquakes was created and the spectral parameters of the events were estimated. Scalar seismic moment varied from $10^{10}$ to $10^{14} \mathrm{Nm}$. The range of SV-wave energy is from $10^{3}$ to $10^{9} \mathrm{~J}$. The static stress drops calculated from S-waves vary between 0.02 to $35 \mathrm{MPa}$. The relationships between stress drop and scalar seismic moment undoubtedly show that the stress drop increases with seismic moment. Nevertheless, the scattering of the static stress drop or apparent stress drop around a fixed seismic moment spans roughly 1.5-2 orders of magnitude.

\section{Conclusion}

This paper reviewed the outcomes of the Japanese-South African collaborative research, highlighting stress measurements, AE and strain monitoring, laboratory experiments and the enhanced CGS's surface South African National Seismograph Network.

$\mathrm{BX}$ CCBO in situ stress measurements have been carried out at seven sites at depths between 1 and $3.4 \mathrm{~km}$ below surface in South African gold mines. The measured $\sigma_{1}$ ranges between 80 and $146 \mathrm{MPa}$. Those were significantly beyond the ranges of depth from surface and stress in previously published measurement results in South Africa. The BX CCBO technique proved suitable for adverse conditions in deep and highly stressed South African gold mines where only small exploration drilling machines are available. The in situ measured stresses confirmed that the assumption of a far-field (initial) stress gradient was acceptable with only slight modifications. An improved estimation of the far-field stress gradient allowed us to better constrain both the stress and strength of the earthquake faults of $M_{L}=2.1$ to 4 , with $\sigma_{1}$ ranging between 100 and $177 \mathrm{MPa}$. The stress range was also confirmed by analysing breakouts and core discings in a hole drilled through a ML2.1 hypocentre. At one site where $\sigma_{1}$ was $\sim 110 \mathrm{MPa}, \mathrm{BX}$ CCBO and CSIRO HI cell measurements were compared and good agreement between the two measuring techniques was found. However, the comparison identified a small problem with the BX CCBO system, which will subsequently be addressed.

Twelve Ishii strainmeters, which are much more sensitive and stable over time than civil engineering strainmeters, were installed in five gold mines below pillars in a rock mass that behaves elastically where the rock mass responds elastically to mining. Comparisons between the site recordings and elastic boundary element simulations allowed us to evaluate the inelastic rock mass effects on stress evolution beneath the pillars associated with mining.

Several tens of AE sensors were deployed to monitor 3D microfracturing induced by the mining of a shaft pillar in a volume of a few hundred metres in size. The AE network detected and accurately located at least 300 times more events than the in-mine seismic system. The AE monitoring delineated multiple planar structure of activity. Several triaxial accelerometers allowed the calibration of AE sensors and the determination of moment magnitude. The $b$ value for the cluster thus obtained just ahead of a stope panel was 1.2, which contradicted a suggestion by Richardson and Jordan (2002) that new fractures generated by blasting disturb the size distribution of background events. 
Lab experiments are being carried out in association with the above activities on a core sample collected near the hypocentre of the $M_{L} 2.1$ event. This produced interesting results that are relevant to studies of the scale dependency in fracturing.

CGS deployed three dense strong motion seismograph surface networks to record strong motions fully that are clipped with the geophones that are typically used by in-mine networks. An improved automatic event location algorithm by Horiuchi et al. (2011) was introduced, producing very good clustering of seismic events within mining boundaries without the problem of spurious and false locations. The results were very pleasing and will assist in the manual picking of events. The results of routine processing of spectral parameters indicate that the reliable estimation of source parameters of earthquakes can be achieved for distances of less than $80 \mathrm{~km}$ between seismic source and stations.

\section{Acknowledgement}

We thank Anglogold Ashanti, Goldfields, Sibanye Gold, First Uranium, Gold One and their employees for kindly facilitating our project. Seismogen and Open House Management Solutions let us work with good technicians, especially, the late Gilbert Morema, Sifiso Khambule, Thabang Masakale, Raymond Vermeulen, and Sylvester Morema. Drilling was done by Lesedi, Rosond, and Murray and Roberts. Akema boring and Techno Sugaya assisted stress measurements and strain monitoring, respectively. In addition to the authors, colleagues from ISS International, Institute of Mine Seismology, CSIR and CGS also contributed to the project greatly. For administration, Japan Science and Technology agency (JST), Japan International Cooperation Agency (JICA), Ritsumeikan University, in particular, Koichiro Miyara, Jun Takashima, and Akiko Kamito made valuable contribution. Our activities have been supported by JST-JICA Science and Technology Research Partnership for Sustainable Development. The monitoring is also partly supported by the Grant-in-Aid for Scientific Research by Japan Society for the Promotion of Science (No. 21224012, 21246134), under its Observation and Research Program for Prediction of Earthquakes and Volcanic Eruptions, Ritsumeikan University, and 21 Century COE Program of Tohoku University; the Department of Science and Technology, and the South African Research Chairs initiative. We thank the reviewers for their kind comments that improved the manuscript.

\section{References}

Aki, K 1980, 'Attenuation of shear-waves in the lithosphere for frequencies from 0.05 to $25 \mathrm{~Hz}^{\prime}$, Physics of the Earth and Planetary Interiors, vol. 21, pp. 50-60.

Amadei, B \& Stephansson, O 1997, Rock Stress and its Measurement, Chapman \& Hall, London.

Andrews, DJ 1986, 'Objective determination of source parameters and similarity of earthquakes of different size', in S Das, J Boatwright \& CH Sholtz (eds), Earthquake Source Mechanics, American Geophysical Union, Washington DC, pp. 259-68.

Chamber of Mines Research Organization 1988, An Industry Guide to Methods of Ameliorating the Hazards of Rockfalls and Rockbursts, Chamber of Mines of South Africa, Johannesburg.

Durrheim, RJ, Ogasawara, H, Nakatani, M, Yabe, Y, Milev, AM, Cichowicz, A, Kawakata, H, Murakami, O, Naoi, M, Yoshimitsu, N, Kgarume, T \& the SATREPS Research Group 2012, 'A Japanese - South African collaboration to mitigate seismic risks in mines: establishment of experimental sites', in Y Potvin (ed.), Proceedings of the Sixth International Seminar on Deep and High Stress Mining, Australian Centre for Geomechanics, Perth, pp. 173-187.

Gay, NC 1975, 'In situ stress measurement in southern Africa', Tectonophysics, vol. 29, pp. 447-459.

Handley, MF 2013, 'Pre-mining stress model for subsurface excavations in southern Africa', Journal of the Southern African Institute of Mining and Metallurgy, vol. 133, pp. 449-471.

Hofmann, GF \& Murphy, SK 2007, 'Coulomb stress triggering in the underground mining environment' in E Eberhardt, D Stead \& T Morrison (eds), Proceedings of the First Canada-US Rock Mechanics Symposium, pp. 1415-1422.

Hofmann, GF, Ogasawara, H, Katsura, T \& Roberts, D 2012, 'An attempt to constrain the stress and strength of a dyke that accommodated a ML2.1 seismic event', Proceedings of the Second Southern Hemisphere International Rock Mechanics Symposium, South African Institute of Mining and Metallurgy, Johannesburg, pp. 436-450.

Hofmann, GF, Scheepers, L \& Ogasawara, H 2013, 'Loading conditions of geological faults in deep level tabular mines', in T Ito (ed.), Proceeding of the Sixth International Symposium on In-Situ Rock Stress, Japanese Committee for Rock Mechanics, Tokyo, pp. 558-580.

Hofmann, GF \& Scheepers, LJ 2010, 'Simulating fault slip areas of mining induced seismic tremors using static boundary element numerical modelling', in M van Sint Jan \& Y Potvin (eds), Proceedings of the Fifth International Seminar on Deep and High Stress Mining, Australian Centre for Geomechanics, Perth, pp. 395-412. 
Horiuchi, S, Horiuchi, Y, lio, Y, Sawada, Y, Sekine, S, Nakamura, H, Okada, T, Nakatani, M \& Naoi, M 2011, 'Automatic P and S wave arrival time picking compared to manually picking', Abstracts, IUGG General Assembly, \# 3430.

Jones, RH \& Stewart, RC 1997, 'A method for determining significant structures in a cloud of earthquakes', Journal of Geophysical Research, vol. 102, pp. 8245-8254.

Kim, K \& Franklin, JA 1987, 'Suggested method for rock stress determination', International Journal of Rock Mechanics and Mineral Science and Geomechanics Abstracts, vol. 24, no. 1, pp. 53-73.

Kwiatek, G, Plenkers, K, Dresen G \& JAGUARS Group 2011, 'Source parameters of picoseismicity recorded at Mponeng deep gold mine, South Africa: Implications for scaling relationship', Bulletin of Seismological Society of America, vol. 101, pp. 2592-2608.

Kwiatek, G, Plenkers, K, Nakatani, M, Yabe, Y, Dresen, G \& JAGUARS-Group 2010, 'Frequency-magnitude characteristics down to magnitude -4.4 for induced seismicity recorded at Mponeng gold mine, South Africa', Bulletin of Seismological Society of America, vol. 100, pp. 1165-1173.

Leeman, ER \& Hayes, DJ 1966, 'A technique for determining the complete state of stress in rock using a single borehole', Proceedings of the First Congress of the International Society for Rock Mechanics, vol. 2, pp. 17-24.

Lucier, AM, Zoback, MD, Heesakkers, V, Reches, Z \& Murphy, SK 2009, 'Constraining the far-field in situ stress state near a deep South African gold mine', International Journal of Rock Mechanics and Mining Sciences, vol. 46, pp. 555-567.

Moriya, H, Naoi, M, Nakatani, M, Kgarume, T, Ward, AK, Durrheim, RJ, Joachim, P, Yabe, Y, Kawakata, H \& Ogasawara, H 2013, 'Detection of mining-induced fractures associated with stress perturbation around a stope in Ezulwini gold mine, South Africa, by using AE events', in T Ito (ed.), Proceedings of the Sixth International Symposium on In-Situ Rock Stress, Japanese Committee for Rock Mechanics, Tokyo, pp. 597-602.

Moriya, H, Naoi, M, Nakatani, M, Murakami, O, Kgarume, T, Ward, AK, Durrheim, R, Philipp, J, Yabe, Y, Kawakata, H \& Ogasawara, H 2012, 'Detection of mining-induced fractures around a stope in Ezulwini gold mine, South Africa, by using AE events with similar waveforms', Proceedings of the Twenty-first International Acoustic Emission Symposium, Japanese Society for Non-Destructive Inspection, Tokyo, pp. 181-186.

Nakatani, M 2013, Microfractures on natural faults stressed by mining, in the International Summer School on Earthquake Science: Diversity of Earthquakes, Earthquake Research Institute of the university of Tokyo and the Southern California Earthquake Center, Hakone, 25 September 2013.

Nakatani, M, Yabe, Y, Philipp, J, Morema, G, Stanchits, S, Dresen, G \& JAGUARS Group 2008, 'Acoustic emission measurements in a deep gold mine in South Africa-project overview and some typical waveforms', Seismological Research Letters, vol. 79.

Naoi, M, Nakatani, M, Horiuchi, S, Yabe, Y, Philipp, J, Kgarume, T, Morema, G, Khambule, S, Masakale, T, Ribeiro, L, Miyakawa, K, Watanabe, A, Otsuki, K, Moriya, H, Murakami, O, Kawakata, H, Yoshimitsu, N, Ward, A, Durrheim, R \& Ogasawara, H 2013, 'Frequency-magnitude distribution of $-3.7<\mathrm{Mw}<1$ mining-induced earthquakes around a mining front and $b$ value invariance with post-blast time', Pure and Applied Geophysics, doi 10.1007/s00024-013-0721-7.

Naoi, M, Nakatani, M, Yabe, Y, Kwiatek, G, Igarashi, T \& Plenkers, K 2011, 'Twenty thousand aftershocks of a very small (M2) earthquake and their relation to the mainshock rupture and geological structures', Bulletin of the Seismological Society of America, vol. 101, pp. 2399-2407.

Naoi, M, Nakatani, M, Yabe, Y, Philipp, J \& JAGUARS group 2008, 'Very high frequency AE (<200 KHz) and micro seismicity observation in a deep South African gold mine - evaluation of the acoustic properties of the site by in-situ transmission test', Seismological Research Letters, vol. 79.

Nicolaysen, LO 1992, 'International semi-controlled experiment on seismic events: a review of the background and proposal', News Letters of Seismological Society, Japan, vol. 3, no. 6, pp. 9-27.

Ogasawara, H, Durrheim, RJ, Nakatani, M, Yabe, Y, Milev, A, Cichowicz, A, Kawakata, H, Moriya, H \& JST-JICA SA research group 2009, 'A Japanese - South African collaboration to mitigate seismic risks in deep gold mines', Proceedings of the 1st Hard Rock Safe Safety Conference, Southern African Institute of Mining and Metallurgy, Johannesburg, pp. 115-134.

Ogasawara, H, Kato, H, Hofmann, G \& de Bruin, P 2012, 'Trial of the BX conical ended borehole overcoring stress measurement technique', Journal of Southern African Institute of Mining and Metallurgy, vol. 102, no. 8, pp. 749-754.

Ogasawara, H, Kato, H, Hofmann, G, Roberts, D, Piper, P, Clements, T, Ward, AK, Yabe Y, Yilmaz, H, \& Durrheim, RJ 2014b, 'BX CCBO in-situ stress measurements at earthquake prone areas in South African gold mines - a summary of mini-workshop on 13 Feb 2014', Proceedings of ARMA2014, Minneapolis, on CD-ROM, paper no. 14-7438.

Ogasawara, H, Kato, H, Hofmann, G, Roberts, D, Piper, P, Clements, T, Yabe, Y \& Sakaguchi, K 2013, 'In-situ stress measurements to constrain stress and strength near seismic faults in deep level South African gold mines', in T Ito (ed.) Proceedings of the 6th International Symposium on In Situ Rock Stress, Japanese Committee for Rock Mechanics, Tokyo, pp. 614-623.

Ogasawara, H, Katsura, T, Hofmann, G, Yabe, Y, Nakatani, M, Naoi, M, Ishii, H, Roberts, D, Nakao, S, Okubo, M, Wienand, J, Lenegan, P \& Ward, AK 2014a, 'In-situ monitoring of rock mass response to mining in South African gold mines using the Ishii strainmeters', Proceedings of the Sixth South African Rock Engineering Symposium: SARES 2014, Southern African Institute of Mining and Metallurgy, Johannesburg, pp. 21-34.

Plenkers, K, Kwiatek, G, Nakatani, M, Dresen, G \& the JAGUARS Group 2010, 'Observation of seismic events with frequencies $f$ > $25 \mathrm{kHz}$ at Mponeng deep gold mine, South Africa', Seismological Research Letters, vol. 81, pp. 467-479.

Plenkers, K, Schorlemmer, D, Kwiatek, G \& JAGUARS Research Group 2011, 'On the probability of detecting picoseismicity', Bulletin of the Seismological Society of America, vol. 101, pp. 2579-2591.

Richardson, E \& Jordan, TH 2002, 'Seismicity in deep gold mines of South Africa: implications for tectonic earthquakes', Bulletin of the Seismological Society of America, vol. 92, pp. 1766-1782. 
Sakaguchi, K, Obara, Y, Nakayama, T \& Sugawara, K 1992, 'Accuracy of rock stress measurement by means of conical-ended borehole technique', Journal of Mining and Material Processing Institute, Japan, vol. 108, pp. 455-460.

Sato, H, Fehler, MC \& Maeda, T 2012, Seismic Wave Propagation and Scattering in the Heterogenous Earth, 2nd edn, Springer Verlag, Berlin.

Satoh, T, Lei, X, Nakatani, M, Yabe, Y, Naoi, M \& Morema, M 2013, 'Quasi-static fault growth in a gabbro sample retrieved from a South African deep gold mine revealed by multi-channel AE monitoring', in A Malovichiko \& D Malovichiko (eds) Proceedings of the Eighth International Symposium on Rockbursts and Seismicity in Mines, Geophysical Survey of Russian Academy of Sciences, Obninsk, Mining Institute of Ural Branch of Russian Academy of Science, Perm, pp. 51-60.

Stacey, TR \& Wesseloo, J 1998, 'Evaluation and upgrading of records of stress measurement data in the mining industry', Final Project Report Gap511, Safety in Mines Research Advisory Committee, Johannesburg, pp. 1-31.

Sugawara, K \& Obara, Y 1999, 'Draft ISRM suggested method for in situ stress measurement using the compact conical-ended borehole overcoring (CСO) technique', International Journal of Rock Mechanics and Mining Sciences, vol. 36, pp. 307-322.

Wesseloo, J \& Stacey, TR 2006, 'Updated in situ stress database for Southern Africa', in LL Kjørholt \& Dahle (eds), In Situ Rock Stress, Taylor \& Francis Group, London, pp. 467-471.

Wiles, TD 2011, Map3D: Mine Analysis Package in Three Dimensions, version V58, Mine Modelling Pty Ltd, Mt. Eliza, http://www.map3d.com

Yabe, Y, Nakatani, M, Naoi, M, lida, T, Satoh, T, Durrheim, R, Hofmann, G, Roberts, D, Yilmaz, H, Morema, G \& Ogasawara, H 2013, 'Estimation of the stress state around the fault source of a Mw 2.2 earthquake in a deep gold mine in South Africa based on borehole breakout and core discing', in T Ito (ed.), Proceeding of the Sixth International Symposium on In-Situ Rock Stress, Japanese Committee for Rock Mechanics, Tokyo, pp. 604-13.

Yabe, Y, Philipp, J, Nakatani, M, Morema, G, Naoi, M, Kawakata, H, Igarashi, T, Dresen, G, Ogasawara, H \& JAGUARS Group 2009, 'Observation of numerous aftershocks of an Mw1.9 earthquake with an AE network installed in a deep gold mine in South Africa', Earth Planets and Space, vol. 61, pp. E49-E52.

Yamamoto, K, Kuwahara, Y, Kato, N \& Hirasawa, T 1990, 'Deformation rate analysis: a new method for in-situ stress estimation from inelastic deformation of rock samples under uniaxial compression', Tohoku Geophysical Journal, vol. 33, pp. 1-13. 
